\title{
PERIODISTAS: ¿USAR O NO USAR PRÉSTAMOS? HE AHÍ LA CUESTIÓN
}

\section{JOURNALISTS: TO USE OR NOT TO USE LOAN WORDS? THAT IS THE QUESTION}

\author{
Constanza Gerding Salas \\ Universidad de Concepción, Chile. \\ cgerding@udec.cl \\ Paola Cañete González \\ Universidad de Concepción, Chile. \\ pcanete@udec.cl \\ Carolin Adam \\ Universidad de Concepción, Chile. \\ cadam@udec.cl
}

\section{Resumen:}

Durante los últimos años, la Antena Chilena de Neología de la Universidad de Concepción ha centrado su investigación en la innovación léxica mediante préstamos de otras lenguas, principalmente del inglés. En este trabajo se profundiza en el estudio del uso de estas unidades léxicas en la prensa escrita chilena, pero esta vez desde el punto de vista de quienes probablemente cuentan entre los principales propagadores de neologismos: los periodistas. Para ello, se aplicó un cuestionario semiestructurado a periodistas en ejercicio de la profesión en diversos ámbitos con el fin de indagar acerca de las razones por las que utilizan préstamos, las restricciones institucionales con respecto al uso de estas unidades léxicas y la importancia del rol del periodista en la incorporación de préstamos en español, entre otras. Los principales resultados mostraron una leve diferencia porcentual entre aquellos periodistas que admitieron utilizar préstamos en sus textos y aquellos que señalaron no utilizarlos; además, se estableció la predominancia del inglés como lengua de procedencia de estas voces. Entre sus motivaciones para usar préstamos, los periodistas revelaron la necesidad de llenar vacíos denominativos y semánticos, el uso extendido de ciertas unidades léxicas extranjeras aceptadas por los hablantes y la intención de enriquecer estilísticamente el texto. Por último, se constató que la mayoría de los periodistas reconoce la importancia de su propio rol en la incorporación y el uso de préstamos en español y en su divulgación a través de la prensa.

Palabras clave: préstamos lingüísticos, periodistas, cuestionario

\begin{abstract}
:
The Antena Chilena de Neología housed at the Universidad de Concepción has, in the past few years, focused its research on lexical innovation via loanwords, mainly from English. The present study furthers into the use of these lexical units in Chilean press, but this time from the viewpoint of those who probably count among the main spreaders of neologisms: journalists. To this end, a semi-structured questionnaire answered by journalists working in various fields inquired about the reasons why they used loanwords, the restrictions
\end{abstract}


imposed by their employers regarding the use of these lexical units, and the importance of their own role in the incorporation of loanwords into Spanish, among others. The main results showed a slight percentage difference between those journalists who reported using loanwords in their texts and those not using them; in addition, the predominance of English as the source language of these loanwords was confirmed. Among the reasons for using loanwords, journalists revealed the need to fill lexical and semantic gaps, the widespread use of certain foreign lexical units generally accepted by speakers, and the intention to improve style. Finally, it was found that most journalists recognize the importance of their own role in the incorporation and use of loanwords in Spanish and their dissemination through the press.

Keywords: loanwords, journalists, questionnaire

Recibido: 27 de marzo de 2018

Aceptado: 27 de abril de 2018

\section{Introducción}

Desde la perspectiva de la lingüística diacrónica, Vallès (2002) plantea que un neologismo es una palabra nueva cuando se la contrasta con la lengua que usa una comunidad linguiística en una época pretérita y tiene, por lo tanto, una dimensión social y una temporal. En la misma línea, Rondeau (1983) sostiene que la neología está ligada al dinamismo de las lenguas vivas, no obstante la impresión de estabilidad que los hablantes puedan tener de ellas: las lenguas vivas se caracterizan por una constante incorporación de nuevas voces a su repertorio, lo que, junto con otros rasgos, constituye un indicador manifiesto de su vitalidad.

Las nuevas voces o neologismos léxicos pueden formarse a partir de tres mecanismos específicos: los recursos formales propios con que cuenta cada lengua para crear palabras, incluida la asignación de nuevos sentidos a voces ya existentes (neologismos semánticos), los préstamos y las creaciones ex nihilo (Cabré, Bayà, Bernal, Freixa, Solé y Vallès 2002). La observación de la aparición y el estudio sistemático de estas formas de innovación le competen a la neología léxica, campo de investigación de la Antena Chilena de Neología de la Universidad de Concepción (AChN-UdeC). Este grupo forma parte de las Antenas Neológicas, red de neología del español creada en 2002, cuyos objetivos son analizar los recursos de innovación léxica para contribuir a la descripción de las distintas variedades lingüísticas del español, difundir los nuevos hallazgos y contribuir a 
la actualización de obras lexicográficas de lengua general (Antenas Neológicas). Para dichos propósitos, esta red internacional, constituida por nodos de Argentina, Chile, Colombia, España, México y Perú, cuenta con un corpus de neologismos de las distintas variedades del español, con un caudal que supera las diez mil unidades anuales (Antenas Neológicas).

Tras casi una década y media de observación de las nuevas acuñaciones detectadas en periódicos, la red Antenas Neológicas ha constatado la presencia de neologismos léxicos formados mediante diversos mecanismos de creación, y los distintos nodos han participado en investigaciones colectivas o han realizado estudios propios para explicar la creatividad léxica del español actual. En los últimos años, la $\mathrm{AChN}-\mathrm{UdeC}$ ha centrado su exploración en la innovación léxica mediante unidades provenientes de distintas lenguas (Fuentes, Gerding Salas, Pecchi, Kotz y Cañete 2009) y, más específicamente aún, en la adopción o la adaptación de voces de origen anglosajón (Gerding y Fuentes 2011; Gerding, Fuentes, Gómez y Kotz 2012; Gerding, Fuentes y Kotz 2012; Gerding-Salas, Fuentes, Gómez y Kotz 2014).

Estas voces pueden ser préstamos o calcos. Los préstamos son unidades de una lengua extranjera que se incorporan al español, con o sin adaptación (Observatori de Neología 2004), mientras que los calcos son producto de la traducción literal de una palabra o de un sintagma proveniente de otro idioma. En el presente estudio se emplea el término 'anglicismo' para todas aquellas unidades adoptadas o adaptadas del inglés. En algunos casos, las voces de origen inglés permanecen en su forma original, mientras que, en otros casos, se adaptan ortográficamente para facilitar su asimilación a la lengua española.

Según Domínguez Mejías (2002), existen diferentes maneras de adaptar anglicismos al español. En primer lugar, la autora menciona la adaptación fonética, que por lo general consiste en la introducción de tildes, como en cómic o túnel. En otros casos, se trata de cambios ortográficos en las voces anglicadas, para posibilitar que los hispanohablantes las puedan reproducir como se pronuncian en inglés. A esta última categoría pertenecen voces inglesas como whisky o scanner, para las que la RAE aconseja la grafía güisqui y escáner, respectivamente.

En segundo lugar, esta misma autora propone la categoría de adaptación gráfica, que consiste en cambiar ciertas combinaciones de letras que no existen en la lengua española, 
como 'oo' y 'ck'. Por esta razón, se pueden encontrar formas ortográficas como crac para crack, o zum para zoom. Igualmente, a este grupo de adaptaciones pertenece el uso de guion, como en el caso de top-model, que en inglés se escribe top model.

La tercera categoría de adaptaciones que describe Domínguez Mejías (2002) es la adaptación gramatical, que frecuentemente afecta a los sustantivos. Debido a que en inglés los sustantivos no suelen distinguirse según género, al introducirlos al español, donde esta distinción es obligatoria, se vuelve necesario establecer el género al que pertenecen las voces anglicadas. En algunos casos, también se hace imperioso determinar la formación del plural debido a las reglas gramaticales propias de cada lengua.

La cuarta y última categoría, según la autora, corresponde a la adaptación semántica, en la que una voz anglicada experimenta un cambio de significado, que generalmente es una restricción semántica, como en el caso de gang, que en inglés no necesariamente tiene el sentido negativo que tiene en español.

Además, existen formas neológicas híbridas, es decir, estructuras que combinan "un elemento patrimonial con otro de carácter foráneo" (Estornell Pons 100). Según la autora, los casos más frecuentes dentro de esta categoría son aquellos en los que una voz patrimonial precede a un anglicismo, tal como en pantalla touch o contratar online.

Tal como resalta Delgado Álvarez (2005), muchos de estos anglicismos se introducen al idioma español aun cuando existen equivalentes, como es el caso de sponsor por patrocinante, o manager, por gerente. En otras instancias, se emplean anglicismos por causa de un vacío léxico, como ocurre, por ejemplo, en casting, rating o doping (Delgado Álvarez 92).

Ahora bien, uno de los medios más apropiados para observar el uso y la propagación de las distintas formas anglicadas, así como también de los demás tipos de creación léxica, es la prensa, como señala Ortega:

El lenguaje periodístico es una fuente inagotable de creatividad léxica. Abarca numerosas áreas de conocimiento: economía, política, medicina, deporte... Refleja los cambios lingüísticos que se producen constantemente en la lengua; revitaliza palabras caídas en desuso, une otras que nunca antes se habían asociado, forma compuestos nuevos con palabras griegas, o latinas; emplea por primera vez vocablos extranjeros... Es, por tanto, la fuente renovadora de léxico 
más eficaz con la que cuenta el hablante de español para constatar la vitalidad de nuestro idioma (Párr. 3).

En efecto, el lenguaje periodístico, cuya misión es comunicarse con el receptor, se caracteriza por una serie de aspectos propios del quehacer de la prensa. Por una parte, está la premura con la que se produce el trabajo de los periodistas. Ortega (2001) señala que estos profesionales redactan artículos en un tiempo breve, por lo que emplean mecanismos que apuestan por una expresión clara y concisa para que la comunicación con el lector se establezca rápida y eficazmente. Por otra parte, están los diferentes géneros que componen este lenguaje. Autores como Méndez (Los Neologismos 2011) señalan que el estilo periodístico es una mezcla de géneros: el lenguaje científico o técnico; el lenguaje literario, que suele apreciarse en columnas de opinión y en crónicas deportivas; el lenguaje administrativo y político, utilizado principalmente en crónicas sobre actos oficiales, leyes, entre otros; el lenguaje de divulgación y el lenguaje coloquial, empleados para crear una comunicación más estrecha con el lector. Esta mezcla de géneros da como resultado un lenguaje complejo y con diversas características difíciles de unificar o de describir de manera general.

Una de las causas de esta diversidad de géneros son las distintas secciones que componen un periódico, con temáticas tanto generales como especializadas, cada una con un lenguaje particular. Estas diferencias se reflejan también en el uso de neologismos, ya que la creación o el uso de palabras nuevas se ven favorecidos en determinadas áreas debido a su temática o a características específicas. Por ejemplo, como señala Isla (2005), los dominios científicos y técnicos son más proclives a la creación de palabras debido a la constante necesidad de nombrar nuevas realidades, aunque también se observa una gran producción neológica en el ámbito literario, publicitario y político.

Ahora bien, los neologismos surgen por diversas razones: necesidad denominativa, deseo de expresividad por parte del hablante, prestigio, necesidad de hacer una aclaración, moda o influencia extranjera (Deroy 1971; Mounin 1990; Cabré 1993; Alvar Ezquerra 1999; Sablayrolles 2003; Diéguez 2004; Gerding et al., El Préstamo 2012, Gerding et al., Anglicismos 2012; Guerrero Ramos 2013; Gerding-Salas et al. 2014). Estas razones, muchas veces acompañadas de la premura con la que deben escribir los periodistas, provocan la aparición de neologismos creados con recursos propios de la lengua, pero 
también mediante el uso de préstamos de otras lenguas. En esta situación, como argumenta Alvar Ezquerra (1998), ante la duda de si una palabra existe o no, los periodistas usan marcas tipográficas para señalar que se trata de un uso nuevo, de un valor no consignado en el diccionario o de una palabra "inexistente" (tomada de otra lengua, creada para la ocasión, o con un valor no habitual).

Entre las marcas tipográficas más utilizadas cabe destacar el uso de la cursiva, la negrita y las comillas. De acuerdo con Solé (2002), la letra cursiva predomina mayoritariamente en préstamos tomados intactos de otras lenguas, en neologismos semánticos prestados a un área temática diferente, en usos metafóricos, en neologismos argóticos y en unidades que corresponden a grados de formalidad más bajos que los que demanda el texto, mientras que los neologismos formales (derivados y compuestos) normalmente se marcan en menor grado. Lo anterior, según la autora, no quiere decir que el emisor considere cualquier unidad léxica marcada como un neologismo, sino que muchas veces sólo puede ser un recurso para facilitar la comprensión o destacar aspectos relevantes. En algunos casos, tanto el uso de marcas tipográficas como la postura con respecto al uso de neologismos en textos periodísticos están determinados por las normas definidas por los manuales de estilo, que cumplen una función prescriptiva que busca "unificar sistemas y formas expresivas con el fin de dar personalidad al propio medio y facilitar la tarea del lector" (Cit. en Perdiguero 89).

Los manuales de estilo son un conjunto de normas internas de cada periódico cuyo propósito es reglamentar el uso, para resolver dudas y guiar el uso correcto del español. Casi todos estos cuerpos normativos constan de dos partes: una de normas linguísticas sobre cuestiones fonéticas, gramaticales y léxicas y la otra de normas estilísticas del periodismo.

Uno de los aspectos que norma la parte lingüística de estos manuales es el uso de neologismos y específicamente de préstamos (Guerrero Ramos 2006). Algunos manuales son tolerantes con el uso de neologismos y de préstamos (pero restrictivos con respecto al uso de barbarismos) e incluso recomiendan la naturalización de palabras provenientes de otras lenguas, ya sea que estén incorporadas o no en obras lexicográficas del español (Cit. en Fundación EFE 1992). 
Sobre la base de lo señalado precedentemente, se puede aseverar que el lenguaje periodístico, por su capacidad de difusión e influencia, lleva a los periodistas a convertirse en modelo para mucha gente (Méndez, De cómo2011); por esta razón, resulta importante estudiarlo, sobre todo si se consideran los acelerados cambios de la actual sociedad de la información. A raíz de constataciones en trabajos anteriores de la AChN-UdeC (Fuentes et al. 2009; Gerding y Fuentes 2011; Gerding et al., El Préstamo 2012; Gerding et al., Anglicismos 2012; Gerding-Salaset al. 2014), que dan cuenta de la alta frecuencia y recurrencia del uso de voces anglicadas en prensa en español, se ha estimado ineludible dilucidar la responsabilidad que podría caberle en la explicación de estas manifestaciones a los periodistas como constructores de realidades y potenciales propagadores de usos lingüísticos.

\section{Metodología}

Con la finalidad de consultar a los propios actores del quehacer periodístico, se diseñó un cuestionario de encuesta que permitiera operacionalizar la observación del fenómeno. Se optó por el cuestionario electrónico, una herramienta de sondeo estándar para encuestas por muestreo, ya que representa la forma más expedita de llegar a grupos de informantes anónimos, que disponen de poco tiempo y que, aun así, manifiestan su voluntad de colaboración. Sin embargo, este tipo de consultas presenta algunas debilidades: el número de respuestas que entrega no es elevado, lo que puede conducir a una muestra no del todo representativa, y por esta misma razón, hay mayor probabilidad de sesgo en la muestra.

El cuestionario se elaboró con la versión básica de la plataforma Survey Monkey® (2017), una herramienta web para la creación de encuestas disponible en línea que permite diseñar consultas personalizadas, enviarlas a los informantes a través del correo electrónico, recoger, almacenar, consultar y reordenar resultados, tabularlos y graficarlos, y realizar algunos análisis estadísticos. Entre las desventajas de la versión básica se puede mencionar que el usuario no puede acceder a todas las herramientas, tales como el filtro de datos o la exportación de los mismos a otro software.

De las opciones que propone este software, se eligió el cuestionario semiestructurado, que constaba de dos tipos de interrogantes: por un lado, las preguntas de respuesta cerrada (dicotómicas, categorizadas o de valoración) y, por otro lado, preguntas 
de respuesta abierta. El primer tipo de preguntas permite al informante seleccionar alternativas prediseñadas, mientras que el segundo tipo le permite enunciar libremente las respuestas de manera más personal.

Previo a la aplicación del instrumento, se realizó una prueba piloto con una muestra de cinco periodistas, lo que permitió verificar la inteligibilidad de las preguntas, detectar valores inesperados en las respuestas y medir el tiempo requerido para contestar el cuestionario. Con los comentarios realizados por los informantes en el piloteo se realizaron mejoras en algunos aspectos del instrumento; por ejemplo, se simplificó el léxico en algunos enunciados.

La muestra estuvo constituida por periodistas en ejercicio de la profesión en diversos ámbitos y se les contactó vía correo electrónico. Sus direcciones electrónicas se obtuvieron a través de jefes de prensa y jefes de servicio de empresas e instituciones de diversos lugares del país. Se contactó de forma personal al jefe de prensa de un periódico local y al director académico de la carrera de periodismo de la Universidad de Concepción. Además, a través de los contactos de las investigadoras, se solicitó la difusión del instrumento con el propósito de ampliar la cobertura a nivel nacional. Si bien se envió el cuestionario de forma directa y a través de contactos a varios centenares de potenciales informantes, se obtuvo respuesta de 52 periodistas.

El cuestionario se dividió en dos partes: una de información personal general sobre el periodista-informante anónimo, como edad, género, ámbito de desempeño laboral, especialidad en la que ejercía y años de experiencia laboral, y la otra constó de 14 preguntas específicamente relacionadas con el uso de préstamos. De estas se seleccionaron las que se relacionaban con la decisión de usar o no préstamo, la procedencia de estos, las razones de su uso, la adopción intacta o la adaptación ortográfica de los préstamos, los motivos de la adopción o adaptación, el uso de marcas tipográficas para etiquetar los préstamos, las restricciones institucionales con respecto al uso de préstamos, las recomendaciones sobre el uso de la lengua materna durante la formación académica inicial y la importancia del rol del periodista en la incorporación de préstamos en el español. Las respuestas de la primera parte permitieron realizar análisis cuantitativos más precisos, 
mientras que las dela segunda parte dieron lugar a análisis principalmente de tipo cualitativo.

\section{Resultados}

Sobre la base de la metodología explicada precedentemente, se presentan a continuación los resultados de este trabajo considerando dos dimensiones: a) caracterización general de los informantes y b) uso de préstamos en la redacción de textos periodísticos.

Del total de 52 periodistas que respondió el cuestionario, $50 \%$ fueron de sexo femenino y $50 \%$ de sexo masculino. De este modo, la muestra quedó conformada de forma homogénea con respecto al sexo de los periodistas encuestados, lo que reflejaría una cierta paridad de género entre personas que acceden a la carrera de periodismo en Chile en la actualidad (Muñoz Montenegro, 2012).

La distribución de los informantes por edad arrojó que un poco más de la mitad de la muestra estuvo constituida por dos grupos correspondientes al rango etario 31-35 años, seguido de cerca por el rango etario 36-40 años (ver Fig. 1), los que junto con el tercer grupo, constituido por el rango etario 41-45 años, representan el 69\% de la muestra. El 31\% restante se distribuyó entre los demás rangos etarios, con una incidencia igual o inferior a diez puntos porcentuales cada uno (ver Fig. 1).

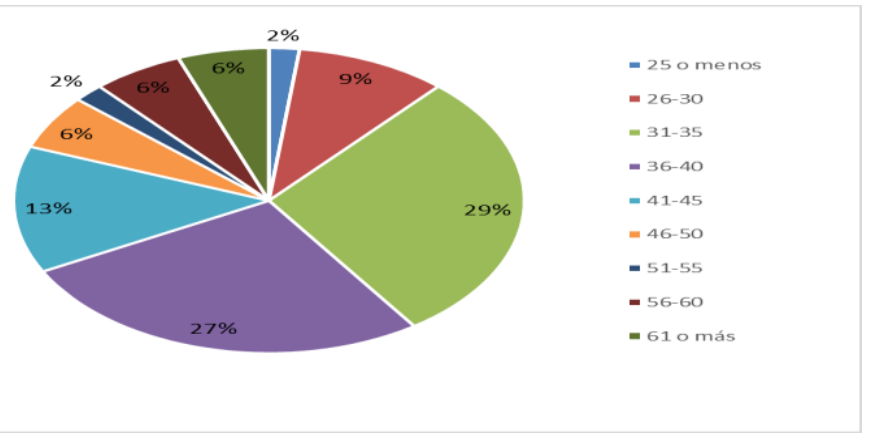

Figura 1. Edad de los periodistas informantes por rango etario $(\mathrm{N}=52)$

Lo anterior demuestra la heterogeneidad de la muestra en este aspecto, lo que permite suponer un buen grado de representatividad etaria, no obstante concentrarse las edades mayormente en informantes entre 31 y 45 años de edad. Es posible que la mayor cantidad de respuestas provenientes de este rango etario se deba a que a esta edad los periodistas muestran mayor disposición a responder encuestas por internet. Por otra parte, 
se determinó que la edad cronológica estaba en consonancia directa con la experiencia laboral de los informantes, ya que más de la mitad de los periodistas admitió tener una práctica de entre 6 y 20 años.

En cuanto al ámbito de desempeño laboral, 38\% de los encuestados indicó que ejercían como redactores de prensa y radio. En segundo lugar, dos grupos iguales (21\% c/u) informaron que se desempeñaban en tareas afines al periodismo en el sector público o en la empresa privada. Dichas tareas por lo general estaban asociadas a las relaciones públicas en departamentos de comunicaciones de empresas e instituciones a nivel nacional o internacional, aunque también en el marketing, la publicidad, los derechos humanos y el ámbito de la energía (ver Fig. 2). En tercer lugar, un 14\% de los encuestados respondió que compartía su labor profesional con la de formador de periodistas en la educación superior. En cuarto lugar, un $4 \%$ informó que su ámbito de desempeño laboral estaba en las redes sociales e internet, y, por último, solo un 2\% (un informante) admitió desempeñarse en el campo de la publicidad. Los ámbitos de desempeño laboral de los periodistas fueron coincidentes con los que figuran como campo ocupacional en la oferta académica de las universidades que imparten la carrera de Periodismo en Chile (ver, por ejemplo, Universidad de Concepción 2018). Dentro de los ámbitos de desempeño laboral, los periodistas indicaron una amplia gama de especialidades, lo que hace que la muestra sea, desde este punto de vista, muy variada.

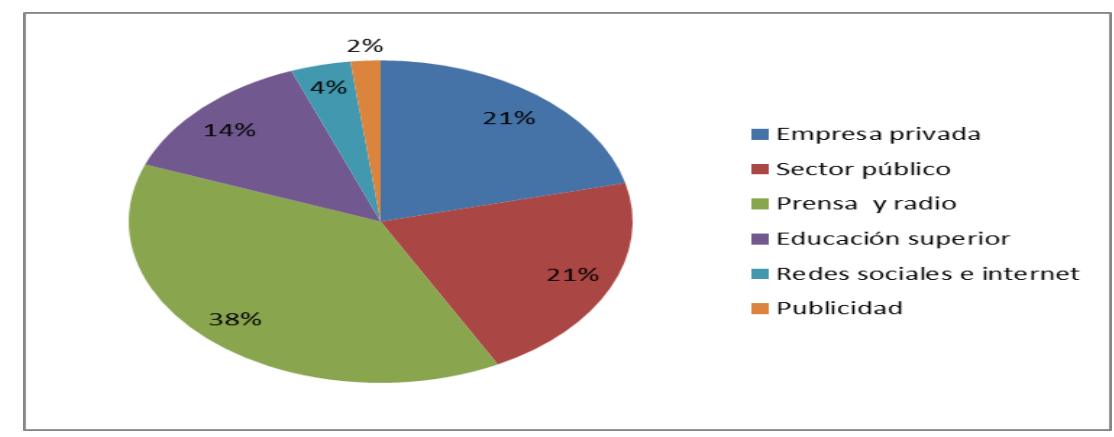

Figura 2. Ámbito de desempeño laboral de los periodistas encuestados

Entre los periodistas que redactaban artículos para medios de prensa convencionales $(\mathrm{N}=20)$, el $60 \%$ se distribuyó en partes iguales entre las secciones Nacional, Deportes y Política y Sociedad, mientras que un 20\% correspondió a los ámbitos de Salud y Opinión, en igual proporción. El $20 \%$ restante se repartió equitativamente entre quienes se 
desempeñaban en la sección de Economía y en la de Cultura y Espectáculo, por un lado, y quienes ocupaban cargos directivos en un medio de prensa, por otro (ver Fig. 3).

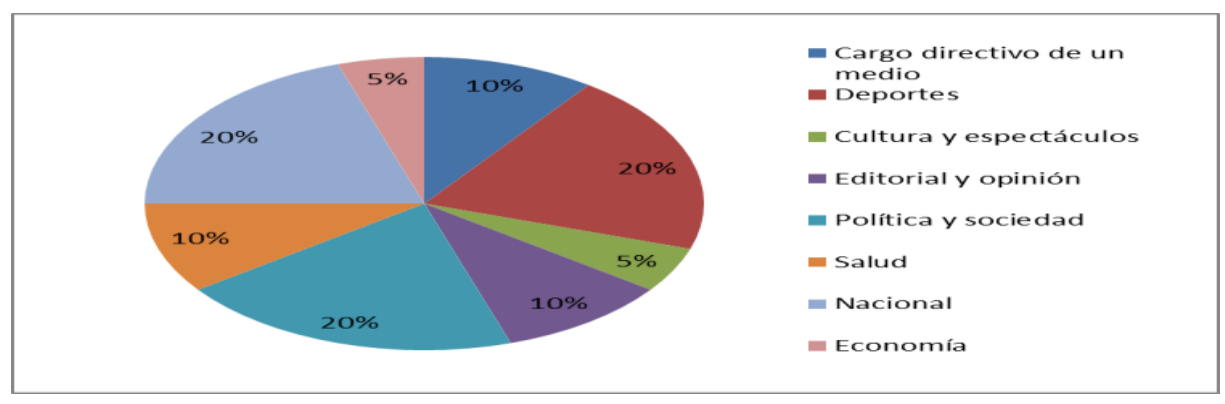

Figura 3. Especialidad en el ejercicio profesional en el medio de comunicación (N=20)

Algunas de estas secciones en las que se desempeñan los periodistas de la muestra (Economía, Deportes y Cultura y Espectáculo) son coincidentes con los ámbitos en los que se manifiesta frecuentemente la creación léxica, especialmente la innovación por la vía del préstamo, como lo respaldan otros estudios realizados por la $\mathrm{AChN}-\mathrm{UdeC}$ (Fuentes et al. 2009; Gerding y Fuentes 2011; Gerding et al., El Préstamo 2012; Gerding at al., Anglicismos 2012; Gerding-Salas et al. 2014) y por otros investigadores (Perdiguero 2003; Diéguez 2004).

Con la excepción de un encuestado (2\%), que omitió responder esta pregunta, un poco más de la mitad de los informantes (56\%) admitió utilizar préstamos de diversas lenguas en sus textos, no siendo muy marcada la diferencia con respecto a quienes señalaron no utilizarlos (42\%). Si bien resulta muy frecuente encontrar en las páginas de los periódicos voces de origen extranjero, Guerrero Ramos (2006) señala que si se toman en cuenta las recomendaciones, no habría que temer al préstamo ni al neologismo en general, ya que su incorporación supondría un enriquecimiento de la lengua.

En relación con las lenguas de procedencia de los préstamos empleados en el lenguaje periodístico, fue ostensible el predominio del inglés frente a todas las demás lenguas mencionadas (ver Tabla 1), lo cual es coincidente con resultados anteriores (Fuentes et al. 2009). Sin embargo, hay una discrepancia entre el estudio citado (con un corpus de 1.440 unidades obtenidas de 86 periódicos chilenos analizados entre 2003 y 2006) y lo referido por los periodistas para el presente estudio: el orden de precedencia de las lenguas que dan origen a préstamos, después del inglés, sitúa a las lenguas originarias en segundo lugar y al francés en tercero (ver Tabla 1), mientras que en el estudio de 
Fuentes y otros (2009) es el francés el idioma que ocupa el segundo lugar. Al respecto, podría hipotetizarse que ha habido una mayor visibilización de las reivindicaciones territoriales del pueblo mapuche en la prensa chilena en años recientes $\mathrm{y}$, como consecuencia, una mayor necesidad de los periodistas de recurrir a préstamos de dicha lengua (lafken, lof, lonko, machi, wallmapu) ante la no equivalencia translémica precisa.

Tabla 1. Lenguas de procedencia de préstamos lingüísticos empleados por los periodistas.

\begin{tabular}{ccc}
\hline Lengua & $\mathbf{N}^{\circ}$ de respuestas & Porcentaje \\
Inglés & 37 & 62 \\
Lenguas originarias: mapudungun, & 9 & 15 \\
aymara, quechua, & & \\
rapa nui & 5 & 8,5 \\
Francés & 3 & 5,0 \\
Italiano & 3 & 5,0 \\
Latín & 1 & 1,5 \\
Alemán & 1 & 1,5 \\
Lenguas asiáticas & 1 & 1,5 \\
Portugués & $\mathbf{6 0}^{*}$ & $\mathbf{1 0 0}$ \\
Total de respuestas & & \\
\hline
\end{tabular}

* El total de 60 respuestas responde a que algunos periodistas indicaron que usaban préstamos provenientes de más de una lengua.

En cuanto a la consulta acerca de las motivaciones que inducían a los periodistas a usar palabras provenientes de otras lenguas, las principales razones esgrimidas por ellos fueron: porque el tema requiere el uso de préstamos que aún no tienen equivalentes, porque su uso se ha extendido y es aceptado por los hablantes, a veces incluso más que su equivalente; porque se trata de un xenismo que llena un vacío semántico en la lengua, o porque se usa como alternativa a una expresión ya existente puesto que enriquece estilísticamente el texto. Aunque menos esgrimidas, otras razones fueron: por moda, por indicación del medio o de la empresa, por falta de aceptación de la unidad léxica del español y porque los préstamos “construyen realidad". Sólo un periodista mencionó que usa únicamente los préstamos que ya han sido incorporados en el Diccionario de la lengua española. Por otra parte, las principales razones esgrimidas por los periodistas para no usar préstamos fueron: porque resultan superfluos si los destinatarios son hispanohablantes y 
porque no contribuyen a mantener la cercanía con el lector. Sostuvieron, aunque con menor frecuencia, que los evitaban porque el usarlos resultaba pretencioso, porque podía afectar la comprensión del lector, por respeto a las normas de su medio laboral o en defensa del correcto uso de la lengua. La variedad de respuestas de los periodistas en este ámbito hace suponer que la inclusión o exclusión de préstamos en el español de Chile no tiene un carácter prescriptivo único o universal, sino que su uso depende de las reglas o instrucciones que cada medio de comunicación establece para promoverlo o restringirlo.

En relación con la naturalización de los préstamos, un 40\% de los periodistas admitió no adaptarlos ortográficamente al español, mientras que un $23 \%$ señaló que los adaptaba. Estos resultados se condicen con estudios anteriores de la $\mathrm{AChN}-\mathrm{UdeC}$, en los que se constató que solamente un porcentaje muy bajo de los préstamos se adapta a la lengua española (Gerding-Salas at al. 2014). Sin embargo, un porcentaje importante de los periodistas (37\%) indicó tener una postura oscilante entre la adopción y la adaptación.

Esta alternancia podría obedecer a razones de diversa índole estilístico-discursiva en dependencia del tema del que se trate, del propósito y la intención del texto, de los destinatarios, del registro lingüístico, del medio de publicación o del contexto geográfico o social.

En cuanto a los motivos que generaban la adaptación ortográfica de los préstamos, fueron cuatro los argumentos más frecuentes: en primer lugar, para facilitar la comprensión al lector; en segundo lugar, porque dichos préstamos tienen un uso extendido, en tercero, por respeto a la lengua española y, en cuarto, por cumplir las normas del medio para el que trabajaban. Por otra parte, la respuesta más frecuente de los periodistas que señalaron no adaptar los préstamos fue el respeto a la lengua de origen. Otras de las razones mencionadas fueron el deseo de no confundir al lector, el apego a las normas de la Real Academia Española, el hecho de que se trate de lenguaje de especialidad y el uso más extendido de la voz inglesa que su equivalente en español. En este contexto, se debe mencionar que la Real Academia Española propone la adaptación de algunas voces de origen extranjero para "preservar el alto grado de cohesión entre forma gráfica y pronunciación característico de la lengua española" (Real Academia Española, Tratamiento Párr. 7). En cambio, entre voces para las que no se recomienda la adaptación ortográfica se encuentran extranjerismos cuyo uso ya se ha expandido en el mundo hispanófono, tales 
como jazz, software o blues. En la adaptación de préstamos se podrían sugerir otras razones que, si bien obedecen a modificaciones inintencionadas, suelen manifestarse con frecuencia en los textos periodísticos: las erratas por la prisa al redactar o el desconocimiento y la falta de verificación de la ortografía original.

Por otra parte, en relación con las indicaciones que hacen los redactores acerca de la condición de préstamo de una unidad léxica, diversos estudios realizados en prensa chilena por la AChN-UdeC han demostrado que cerca de $30 \%$ de los préstamos son marcados tipográficamente y que parece no haber consistencia con respecto al uso de las distintas marcas (Gerding-Salas et al. 2014): algunos préstamos se marcan en letra cursiva, otros con comillas y, muchas veces, estos mismos préstamos no se marcan tipográficamente en otra edición del mismo periódico. La Real Academia Española (Párr. 8), por su parte, sugiere el uso de cursiva o de comillas para todo préstamo no adaptado que ya se ha asentado en el uso internacional. Por estas razones, resulta interesante conocer las apreciaciones de los propios periodistas en relación con el uso o no uso de marcas tipográficas en los préstamos.

De acuerdo con lo que señalaron los encuestados, la gran mayoría indicó usar marcas tipográficas: un $40 \%$ de los periodistas afirmó resaltar siempre tipográficamente los préstamos y un $27 \%$ señaló que sólo a veces empleaba marcas tipográficas, mientras que el $33 \%$ de los encuestados afirmó que no las utiliza. En relación con los motivos por los que se resaltan tipográficamente los préstamos, la gran mayoría de los encuestados que admitió marcarlos señaló que lo hacía con la intención de destacar su condición de préstamo; otros, porque estaban convencidos de que el lector no conocía la palabra o por respeto a las normas, entre las que se mencionaron las del medio, las establecidas por la Real Academia Española y las de la propia formación académica. Entre los motivos menos esgrimidos se encuentran la intención de no confundir al lector, de alertar sobre la pronunciación y de enfatizar. La razón principal que refirieron los periodistas para no emplear marcas tipográficas en los préstamos fue que se trataba de unidades incorporadas en un determinado ámbito, por lo que no consideraban necesario marcarlas.

Con respecto a las restricciones que suelen establecer las instituciones en relación con el uso de préstamos, con la excepción de dos periodistas que no respondieron esta pregunta (4\%), la mayoría de ellos $(84 \%)$ respondió que no se les imponían limitaciones en 
los medios para los cuales trabajaban, y sólo un 12\% reportó la existencia de normas que restringían el uso de préstamos cuando había un equivalente en español o en atención al público al que iba dirigido el mensaje. Estos resultados confirman lo que señala Perdiguero (89): "estas normas de obligado cumplimiento para redactores y colaboradores no han resultado ser suficientes para su cometido o bien no han tenido la influencia esperada". Sin embargo, es importante mencionar que en Chile es muy difícil encontrar manuales de estilo de los periódicos, a diferencia de lo que ocurre en España, por ejemplo. Se les consultó a algunos periodistas de distintas regiones del país y, además, se revisó el catálogo de la Biblioteca de la Universidad de Concepción (en la que se imparte la carrera de Periodismo), pero no se logró tener acceso a estos compendios.

Otro aspecto que se investigó fueron las recomendaciones sobre el uso de la lengua materna que reciben los periodistas durante su formación. A este respecto, un $27 \%$ de los periodistas señaló que durante su formación se les había enseñado a respetar las normas de la lengua, mientras que un 19\% afirmó que la recomendación de sus formadores estaba más bien orientada al uso. Por otra parte, una proporción significativa de informantes destacó que sus profesores aceptaban tanto la postura normativista como la que se define por el uso (44\%). Por último, un $10 \%$ de los periodistas no se inclinó por ninguna de las alternativas propuestas, lo que probablemente se deba a que durante su formación este aspecto no tuvo mayor relevancia (ver Fig.4).

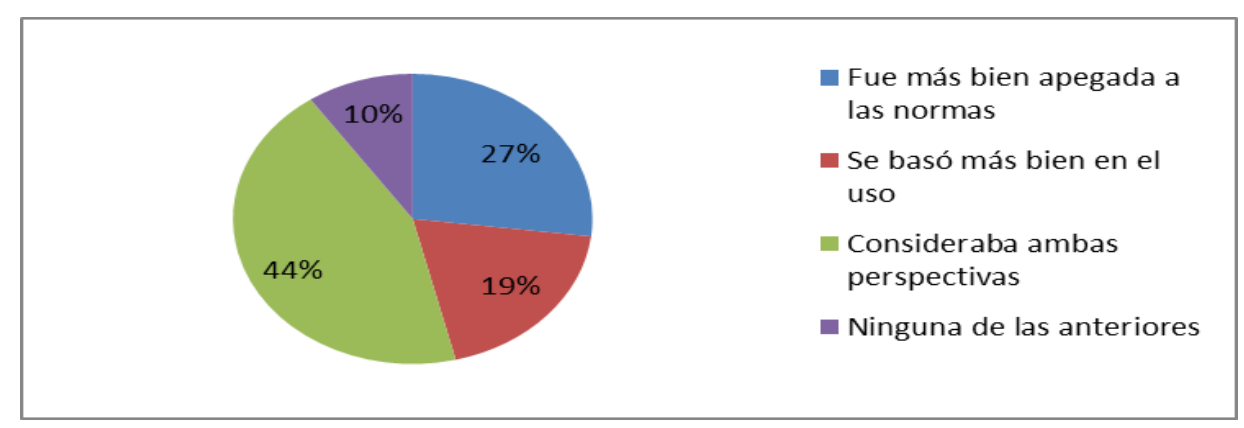

Figura 4. Recomendaciones del uso de la lengua materna en la formación académica del periodista

Frente a la consulta acerca del uso de la lengua materna y de la observancia de las normas que la rigen, los comunicadores les asignaron una importancia relativa. En relación con esto último, Oliva Marañón (12) destaca la importancia de "la competencia lingüística o gramatical (en la formación), referida al dominio del código lingüístico y el conocimiento 
práctico de la estructura, elementos y reglas de la lengua en sus diversos niveles: fonéticofonológico, morfosintáctico y léxico-semántico”. Martínez Albertos (2005), por otra parte, señala que las autoridades encargadas de aplicar las normas son a) una clase cultural prestigiosa, ya que son un modelo de referencia; b) los medios de comunicación de masas, por su extraordinaria capacidad de difusión, y c) las Academias de la Lengua, que verán incrementada su eficacia por una acción coordinada con los medios de comunicación. Sin embargo, a juzgar por lo declarado por los informantes, en este sentido, en el periodismo chileno parece no haber un apego demasiado estricto a la normativa, sino más bien un equilibrio entre estas reglas y lo que dictamina el uso.

Por otra parte, en lo que respecta a la valoración de los periodistas de la importancia de su propio rol en la incorporación de préstamos al español, un $73 \%$ de ellos le atribuyó entre muchísima y mucha importancia a su función en la adopción de este uso linguístico, mientras que un $25 \%$ le asignó relativa importancia a su responsabilidad y solo el $2 \%$ consideró que su rol tenía poca importancia en este hecho.

Se observa, entonces, que los periodistas están conscientes de la relevancia de los medios de comunicación en el uso y difusión de determinadas palabras. Guerrero Salazar (2001) señala que la labor estandarizadora de los medios de comunicación, principalmente de la prensa, se hace más patente en el campo léxico, en especial en lo que se refiere a préstamos y neologismos, y también a la adopción de formas léxicas procedentes de la lengua conversacional. Por su parte, Martínez Albertos (5) señala que "los propios periodistas están también convencidos del destacado rol que hay que adjudicar a los medios de comunicación a la hora de valorar la calidad lingüística de los grupos sociales sobre los que estos medios proyectan sus mensajes" y destaca "el alto grado de responsabilidad que tienen los medios de comunicación respecto de todo lo que tenga que ver con la pureza idiomática del español".

\section{Conclusiones}

Con la certeza de que la prensa es un espacio propicio para la observación del uso de neologismos, el objetivo de este trabajo fue profundizar en el estudio de préstamos y, más específicamente, entender qué papel podía caberles a los periodistas tanto en el proceso de divulgación de este tipo de unidades léxicas neológicas como en su incorporación en el 
español. Por lo tanto, para alcanzar estas metas, se consideró oportuno y pertinente consultar directamente a comunicadores y cronistas laboralmente activos. En este trabajo se han analizado algunos de los aspectos más importantes relacionados con la propia percepción de los periodistas acerca del uso de préstamos en la redacción de textos en su ejercicio profesional.

Si bien en la prensa chilena abundan los préstamos, particularmente los anglicismos en determinados ámbitos del saber, paradójicamente un número importante de periodistasinformantes declara no utilizarlos en la redacción de sus textos. Por otro lado, los comunicadores que admiten usarlos identifican la lengua inglesa como la fuente que mayoritariamente nutre su repertorio lingüístico extranjero, lo que confirma los hallazgos de estudios anteriores de la AChN-UdeC.

Entre las razones por las cuales algunos periodistas emplean préstamos, además de las motivaciones informadas anteriormente por la $\mathrm{AChN}-\mathrm{UdeC}$, los encuestados declaran que, por razones estilísticas, usan voces provenientes de otras lenguas en alternancia con voces existentes en español. Además, proponen que el uso de préstamos a veces contribuye a la "construcción de realidades", es decir, a la creación de verdades socialmente elaboradas. Otro argumento del que se sirven los periodistas es que en ocasiones el uso de préstamos está determinado por las normas de estilo del medio para el cual trabajan. Por otra parte, los encuestados también esgrimen razones que los desincentivan a emplear unidades léxicas de procedencia extranjera, principalmente relacionadas con dificultades tanto en la transmisión como la recepción y comprensión del mensaje.

$\mathrm{Si}$ bien los informantes refieren que los medios pueden, eventualmente, ejercer alguna imposición normativa en cuanto al uso de préstamos, en general, se desprende de las encuestas que el grado de libertad con respecto al uso de la lengua materna del que gozan los periodistas chilenos parece ser alto, realidad que también se ve reflejada en la formación inicial de los periodistas.

En relación con la naturalización de préstamos, se confirma lo observado en estudios anteriores de la $\mathrm{AChN}-\mathrm{UdeC}$ : en la prensa se emplean préstamos mayoritariamente sin modificación ortográfica. Por otra parte, en caso de que haya adaptación de las voces extranjeras en este aspecto, las principales razones aducidas dicen relación con el grado de 
comunicabilidad del mensaje tanto en su emisión como en su recepción, aunque también, en ocasiones, la naturalización obedece a razones prescriptivas.

En relación con el uso de marcas tipográficas para señalar la condición de préstamos de determinadas unidades léxicas, a diferencia de resultados de estudios anteriores de la AChN-UdeC, en que se ha observado la frecuente prescindencia de estas marcas, llama la atención que un número muy importante de periodistas consultados en este estudio manifiesta exactamente lo contrario, y la principal razón esgrimida es la advertencia al destinatario de la condición de préstamo de la unidad empleada.

Por último, ha sido interesante constatar que prácticamente todos los periodistas consultados están conscientes de la responsabilidad que les cabe en la incorporación de préstamos en el español y su divulgación a través de la prensa. Desde esta perspectiva, los próximos trabajos de la $\mathrm{AChN}-\mathrm{UdeC}$ en este ámbito se centrarán en establecer relaciones entre las variables edad/género, las secciones del periódico o el ámbito de desempeño laboral de los comunicadores de la prensa y el uso de voces extranjeras en la redacción periodística.

\section{Bibliografía}

Agencia EFE. El neologismo necesario. Madrid: Fundación EFE, 1992.

Alvar Ezquerra, Manuel."Palabras nuevas en los periódicos de hoy". La lengua española a finales del milenio. Ed. Antonio Álvarez Tejedor. Burgos: Caja de Burgos, 1998. 13-44.

Alvar Ezquerra, Manuel. "El neologismo: caracterización, formación y aceptabilidad". Actas $V$ Jornadas de Metodología y Didáctica de la Lengua Española: El neologismo, España. Eds. José Manuel González Calvo, María Luisa Montero Curiel y Jesús Terrón González. España: Universidad de Extremadura, 1999. 39-66.

Antenas Neológicas. Red Antenas Neológicas. Universitat Pompeu Fabra. 2016. https://www.upf.edu/web/antenas/presentacion\#red

Cabré Castellví, María Teresa. La Terminología. Teoría, metodología y aplicaciones. Barcelona: Antártida-Empúries, 1993.

Cabré, María Teresa, Bayà María Rosa, Bernal Elisenda, Freixa Judit, Solé Elisabet y Vallès Teresa. "Evaluación de la vitalidad de una lengua a través de la neología: a propósito de la neología espontánea y de la neología planificada”. Lèxic i neología, eds. María Teresa Cabré, Judit Freixa y Elisabet Solé. Barcelona, Observatori de Neologia, Institut Universitari de Lingüística Aplicada, Universitat Pompeu Fabra, 2002. 159-201. 
Delgado Álvarez, Alberto. "Los anglicismos en la prensa escrita costarricense”. Káñina, 29 (2005): 89-99.

Deroy, Louis. "Néologie et néologismes: essai de typologie générale". La Banque des Mots, 1 (1971): 5-12.

Diéguez, María Isabel. "El anglicismo léxico en el discurso económico de divulgación científica del español de Chile”. Onomázein, 2. 10 (2004): 117-141.

Domínguez Mejías, Elena. "Los anglicismos en el Diccionario de la RAE (2001)", Panace@, 3. 8. (2002): 28-33.

Estornell Pons, María. "Novedades léxicas en revistas femeninas: procedimientos de formación y valor semántico-pragmático de las unidades". Normas. Revista de Estudios Lingüísticos Hispánicos, 2 (2012): 77-108.

Fuentes Mary, Gerding Constanza, Pecchi Alma, Kotz Gabriela y Cañete González Paola. "Neología léxica: reflejo de la vitalidad del español de Chile". Revista de Lingüística Teórica y Aplicada, 47.1. (2009): 103-124.

Gerding, Constanza y Fuentes, Mary. "Loanwords in the Press: The Influence of English in Chile". XIX FIT World Conference 2011, Proceedings. San Francisco: Ed. American Translators Association, 2011.193-211.

Gerding, Constanza, Fuentes, Mary, Gómez Lilian y Kotz Gabriela. "El préstamo en seis variedades geolectales del español: un estudio en prensa escrita”. Revista Signos, Estudios de Lingüística, 45.80 (2012): 280-299.

Gerding, Constanza, Fuentes Mary y Kotz Gabriela. "Anglicismos y aculturación en la sociedad chilena". Onomázein, 25 (2012): 139-162.

Gerding-Salas Constanza, Fuentes Mary, Gómez Lilian y Kotz Gabriela. "Anglicism: An active word-formation mechanism in Spanish". Colombian Applied Linguistics Journal, 16.1 (2014): 40-54.

Guerrero Ramos, Gloria. "Uso, ¿o abuso? de los neologismos en la prensa”. Corcillvm. Estudios de traducción, lingüística y filología dedicados a Valentín García Yebra. Eds. Consuelo Gonzalo García y Pollux Hernúñez. Madrid: Arco Libros, 2006. 871 888.

Guerrero Ramos, Gloria. "El préstamo lingüístico, uno de los principales procedimientos de creación neológica". Quaderns de Filologia. Estudis lingüístics, 18 (2013): 115130.

Guerrero Salazar, Susana. Voces comentadas del español actual. Málaga: Sarriá, 2001.

Isla, José Daniel. "El español en la prensa. Neología y registros lingüísticos: Los neologismos en suplementos juveniles de diarios nacionales". IX Jornadas Nacionales sobre Normativa del Idioma Español, España. 2005. www.fundlitterae.org.ar/images/archivos/ISLA.doc

Martínez Albertos, José Luis. "La responsabilidad de los comunicadores en el lenguaje de los medios: la corrección académica". Revista Latina de Comunicación Social, 60 (2005). http://www.revistalatinacs.org/200532martinezalbertos.pdf

Méndez, María del Carmen. Los neologismos morfológicos del español en el lenguaje de la prensa. Sarrebruck: Académica Española, 2011.

Méndez, María del Carmen. "De cómo los neologismos enriquecen la lengua”. Río Negro, Argentina. dic. 6 2011. http://www.rionegro.com.ar/diario/de-como-losneologismos-enriquecen-la-lengua-767496-9709-nota.aspx. 
Mounin, Georges. "Quelques observations sur le lexique français d'aujourd'hui". Europe, 738 (1990): 10-18.

Muñoz Montenegro, Marisa. "Mujeres periodistas: Testimonios de ayer y de hoy". Tesis. Universidad de Chile, Chile. 2012.

Observatori de Neologia, OBNEO. Metodología del trabajo en neología: criterios, materiales y procesos. Papers de l'IULA. Sèrie Monografies 9. Universitat Pompeu Fabra: Barcelona, 2004.

Oliva Marañón, Carlos: "La lengua española en la formación del comunicador: reflexiones y perspectivas de futuro". Razón y palabra. 2014. http://www.razonypalabra.org.mx/N/N86/V86/30_Maranon_V86_02.pdf.

Ortega, María Pilar. "Neología y prensa: un binomio eficaz". Espéculo. Revista de Estudios Literarios, 18 (2001). http://www.ucm.es/info/especulo/numero18/neologism.html.

Perdiguero, Hermógenes. "Innovación léxica en la prensa". Actas del XIV congreso internacional de ASELE. 2003. Madrid: Centro Virtual Cervantes, 2003. 88-95. http://cvc.cervantes.es/ensenanza/biblioteca_ele/asele/pdf/14/14_0089.pdf

Real Academia Española. Diccionario de la lengua española (23da. ed.), 2018. http://www.rae.es.

Real Academia Española. Tratamiento de los extranjerismos, 2018. http://www.rae.es/diccionario-panhispanico-de-dudas/que-contiene/tratamiento-delos-extranjerismos

Rondeau, Guy. Introduction à la terminologie. Québec, Gaëtan Morin Éditeur, 1983.

Sablayrolles, Jean-François. "Fonctions des neologismes". Cahier du CIEL, (1993): 53-94.

Solé, Elisabet. "Textos i neologismes". Lèxic i neología. Eds. María Teresa Cabré, Judit Freixa y Elisabet Solé. Barcelona, Observatori de Neologia, Institut Universitari de Linguiística Aplicada, Universitat Pompeu Fabra, 2002. 79-90.

SurveyMonkey. Admisión. https://www.surveymonkey.com/Universidad de Concepción. Periodismo: Admisión, 2018. http://admision.udec.cl/?q=node/75

Vallès, Teresa. "La productividad morfológica en un modelo dinámico basado en el uso y en los usuarios." Lèxic i neología, eds. María Teresa Cabré, Judit Freixa y Elisabet Solé. Barcelona: Observatori de Neologia, Institut Universitari de Lingüística Aplicada, Universitat Pompeu Fabra, 2002.139-15 